Heo, Seunghoon Emilia. Reconciling Enemy States in Europe and Asia. Basingstoke: Palgrave Macmillan, 2012

Reviewed by: Nadiia Koval

Source: Kyiv-Mohyla Law and Politics Journal 1 (2015): 241-244

Published by: National University of Kyiv-Mohyla Academy

http://kmlpj.ukma.edu.ua/ 


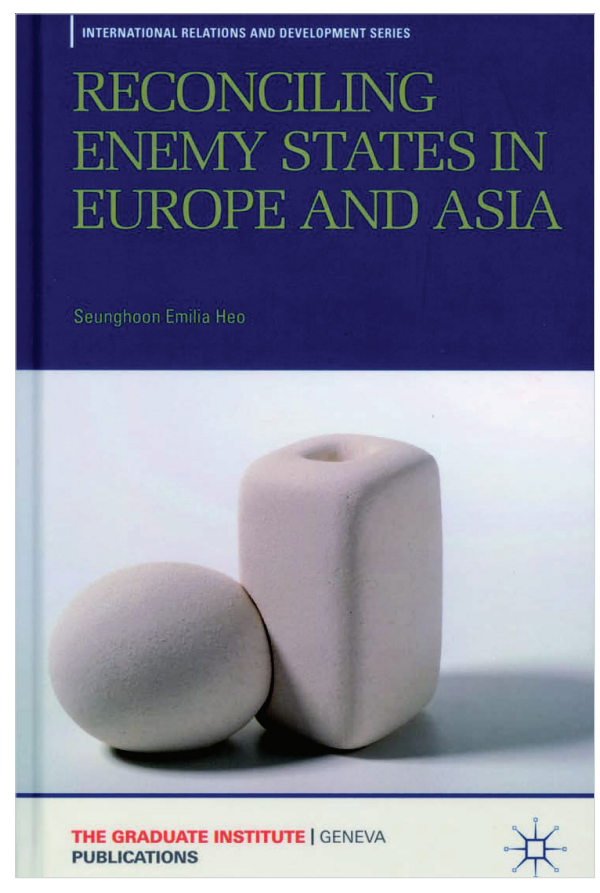

\title{
Seunghoon Emilia Heo
}

\section{Reconciling Enemy States in Europe and Asia}

\author{
Basingstoke: Palgrave Macmillan, 2012. $194 \mathrm{pp}$. \\ ISBN: 978-0230-27988-9
}

\section{Reviewed by Nadiia Koval}

"We are living through a peace epidemic," is how then president of Cyprus George Vassiliou grounded his optimism about launching intercommunal talks designed to successfully resolve the Cyprus problem in September 1988. More than 25 years later, while the Cyprus conflict is still far from resolution, the mentioned "peace epidemic" continues to cover political rhetoric and practice. This poses new challenges to political science as a pure desire to break the vicious circles of war and hatred through dialogue and reconciliation, along with an ethical approach to international relations, which needs workable instruments to come to life in the real world.

"Reconciliation," being a certain buzzword frequently employed by academics, journalists and politicians, is applied in all sorts of contexts - from religion to psychotherapy, from law to politics. Hence, reconciliation studies suffer from the common problem of an overabundance of treatments, a multitude of definitions, and innumerable case-studies without a common or at least coherent theoretical framework. This problem is even more acute within interstate reconciliation studies. The half-hidden nature of most cold-war and post-colonial conflicts, hybrid warfare, and proxy wars permits to claim that most of the conflicts in the present époque were rather intrastate, intercommunal, and interethnic rather than interstate ones. Still, as the cold war has been over for more than two decades, evolution of the world system makes it evident that new alliances, old hatreds, and regional integration necessitate interstate reconciliation for resolving long-term animosities and creating new affections.

Seunghoon Emilia Heo is a collaborator at the United Nations University in Tokyo, an intellectual hub bringing together academics and politicians trying to bridge the gap between expert knowledge and political decision. Thus, Heo underlines the practical utility of the question: "The major utility of interstate or international reconciliation studies is therefore its contribution as a conceptual, empirical, and methodological link between work on the future of the international system and the future of the nation-states whose interrelationships make up 
the system" (p. 5). In other words, she contributes not only to a better understanding of making durable peace, but to making a better world itself.

In recent years interest in interstate reconciliation achieved considerable reflection in academic literature. To name just a few, there is Charles Kupchan's seminal opus How Enemies Become Friends: The Sources of Stable Peace (Princeton University Press, 2010), whose impressive treatise does not use the term "reconciliation" and keeps closer to the more traditional IR theory of stable peace. Besides, several insightful comparative works like that of Lily Gardner Feldman on the German experience in reconciling with France, Poland, Israel, and the Czech Republic (Germany's Foreign Policy of Reconciliation: From Enmity to Amity, Rowman \& Littlefield Publishers, 2012), or of Yinan He (The Search for Reconciliation: Sino-Japanese and German-Polish Relations since World War II, Cambridge University Press, 20o9), provide important theoretical insights, but are limited to their respective cases.

Heo's contribution is different from the aforementioned and some other works because it seeks to build a general theoretical framework for treating interstate reconciliation. In its approach, it appears to be a kind of a textbook for post-conflict resolution professionals and academics, a systematizing all aspects of interstate reconciliation. Therefore, the book's title tends to be slightly misleading, as the author explicitly states that her aim is to study the essence of the term of reconciliation and not the process or eventual recipes for reconciling. Consequently, Heo concentrates much more on the theoretical aspects of reconciliation than on a thorough comparison of the actual experience of different states in Europe and Asia. Of course, the author makes good use of her impressive language capacities and provides plenty of examples. Nevertheless, the book's theoretical construct, and not a case study or in-depth comparison, is its strongest feature.

Looking for a philosophical base for a comprehensive understanding of interstate reconciliation, Heo makes an interesting allusion to the French revolution's classic triad of liberté, égalité, fraternité. While the first two terms — liberty and equality — are well-established and important in contemporary international relations, the third looks underappreciated. Fraternité, or the brotherhood of the nations, might well be used as an imperialist tool — which could be easily illustrated by recent developments in Ukrainian-Russian relations. Still in a more benign way it could and should be reconsidered as a conceptual key to harmony and a normative foundation to stable peace among nations.

To limit the vast field of what reconciliation is and to generate a definitional framework, Heo starts with choosing subjects of reconciliation. Taking a nation-state as a unit of analysis, the author defines these subjects as "dyads that share painful historical events in the past, which left scars either at one side or both the populations; still reflect hostile public mood toward each other deeply engrained at the present; and express collective fear or distrust projected into the future" (p. 37). Numerous authors acknowledge that history comes into action probably even more powerfully in international relations than in the case of intrastate reconciliation. For example, this idea is very close to what Yinan He describes as "deep historical reconciliation" or to the vision of Alexis Heraclides, who claims that true interstate reconciliation is unrealistic and groundless without historical wounds being healed. Still, Heo does not treat historical reconciliation as the most important part or a final stage of the reconciliation process (as the 
aforementioned authors and some others do): for her it is first of all an important prerequisite, a qualifier, a condition sine qua non.

The second line of creating a definitional framework consists of making a distinction with such well-established terms in international relations studies as "alliance"/"entente," "appeasement," "rapprochement," "coexistence," “détente," "normalisation," "rapprochement and special relationship." Convincingly showing that reconciliation cannot be narrowed to any of these terms, Heo concludes that "if reconciliation is not always mutually exclusive with other cooperative behaviours, it still has deeper meaning than any other interstate actions" (p. 61). Her definition of reconciliation is quite encompassing: "The most cooperative behaviour between hereditary enemy states that implies both people and state of each side to transform their mutual relations from a state of war to the state of peace" (p. 61).

In choosing such a wide definition, the author points to the biggest problem of reconciliation studies - the vague and wide nature of the reconciliation phenomenon. Actually it is not as much a definition, but rather a kind of a frame permitting to grasp the nature of reconciliation. According to Heo, state of war could mean everything from the imminent suspension of hostilities to a cold peace or forced coexistence. For this reason the desired state of peace must share two basic characteristics: (1) impossibility of war in the long term or durability of peace (largely based on the stable peace theory), (2) communion or mutual acceptance of the two parts, blessed with a new state of "we-ness," a new common identity.

In a long theoretical debate of whether reconciliation should be the final stage, the very process of amending relations, or both, Heo definitely takes the position that it is a process. In the given framework, reconciliation is presented as a long-term transformational policy that needs strong political willingness "to prefer change to continuity." "This long-term aspect of reconciliation links the past to the present and the present to the future. It also links the governmental level to the population level through reconciliatory politics" (p. 7o).

To analyse the content of this long-term process, Heo adopts the Weberian approach and considers the ideal type of reconciliation as a combination of levels, fields, and actors. First, she identifies three levels of reconciliation - systemic or international level, i.e., external pressure on bilateral reconciliation, regional level, which is about regional cooperative and institutional frameworks, in particular regional integration processes and, finally, domestic level. The last implies bilateral relations between states and is treated in the most detailed way. Heo strictly separates the state-to-state level from the people-to-people level at this domestic stage. For the former, she reserves such fields of reconciliation as politico-diplomatic reconciliation and economic reconciliation, for the latter - socio-cultural reconciliation and historical reconciliation. Such distinctions could be useful for conceptual clarity as they grasp most fields of reconciliation that are met in practice. However, for further studies the questions of the interplay between the different levels, relations between different levels at different stages, direct intervention on regional and systemic pressures in domestic affairs could refine the proposed scheme.

In her final approach, Heo attempts to develop a comparative and evaluative framework to discern which dyads of hereditary enemies are more likely to reconcile. Quantifying occurs through choosing 2 variables: government's attitude and people's attitude. Each has 
two possible values: positive or negative. Applying the approach to relations between two countries, she defines 10 possible combinations, though limiting her analysis just to the four most common. Two of these are extreme: (1) negative symmetry - a situation, when neither the governments, nor the peoples of the two countries wish to reconcile and (2) positive symmetry - a situation, when both governments and peoples are involved in reconciliation. The case when only the governments of both countries are working towards reconciliation, while the public remains hostile, is called common asymmetry. It is conducive to initiating the process, thought somewhat problematic to sustain it. Finally, the case when only societies are engaged in reconciliatory activities despite official governmental positions, is called transitional asymmetry. It is considered to be rather rare, poorly measurable and indeed a transitional process as "it is difficult to intensify interactions between the populations without a governmental engagement" (p. 111). According to the author, "a challenging point here is to work out under which conditions dyads decide to get involved with one of those four patterns" (p. 114). To my mind, some of the asymmetrical models rejected by the author, like that when one government proposes engagement and the other government does not respond, also deserve further scrutiny in comparing practical cases.

In order to analyze the reconciliation process from a qualitative perspective, Heo introduces two qualifiers. The first is based on the nature of power relations, i.e., whether the countries are symmetrical or asymmetrical in power. The author duly acknowledges the difficulties in assessing "power" and the possibility of an eventual evolution of the power balance over time. The second qualifier comprehends the nature of the conflict — whether there was a war clash, a postcolonial struggle or ethnic, religious, and cultural conflict. The result, and partly an answer to the topical question of the book "why some countries reconcile while others do not" is: symmetrical powers that have just had a war are most likely to reconcile. At the same time, conflicts between asymmetrical states whose clashes are motivated by identity formation processes with either ethnic, religious, and cultural issues at stake are the least reconcilable cases. In my opinion, unfortunately this is the type that prevails and indeed rarely succeeds. Moreover, Heo's interpretation suggests that it might be irrelevant to use the French-German case (which could be described as symmetrical and deprived of deep cultural differences) as a basic reconciliation model because most other cases of ongoing conflicts are asymmetrical and relate to identity issues.

In sum, this is a very brave intellectual endeavour, transcending an element-focused approach (i.e., treating reconciliation as forgiveness, healing, justice etc.) as well as case-study bias, "in order to identify the similarities as well as particularities of reconciliation; then to find out quantifiable indicators of measurement viewing it both from diachronic and synchronic dimensions" (p. 13), useful for theoreticians and practitioners of interstate reconciliation alike. Taking into consideration the scope of the study and the impressive results achieved, it would be unfair to demand that the author treats every path proposed in detail. Still, a model for more practical tests and more nuanced approaches is proposed for more balanced academic studies and political decisions. 